(2) Open Access Full Text Article

\title{
Autoinjector preference in multiple sclerosis and the role of nurses in treatment decisions: results from an international survey in Europe and the USA
}

\author{
This article was published in the following Dove Press journal: \\ Pragmatic and Observational Research \\ 12 December 2014 \\ Number of times this article has been viewed
}

\author{
Elisabetta Verdun di \\ Cantogno' \\ Mark Tomlinson' \\ Laure Manuel $^{2}$ \\ Kunal Thakur' \\ 'Novartis Pharma AG, Basel, \\ Switzerland; ${ }^{2}$ Adelphi Research, \\ Bollington, Cheshire, UK
}

Correspondence: Elisabetta Verdun di Cantogno

Novartis Pharma AG, Fabrikstrasse I2, $\mathrm{CH}-4002$ Basel, Switzerland

Tel +4 I 6I 3244025

Fax +4I 6I 6968030

Email elisabetta.verdun@novartis.com
Purpose: This international survey recorded the opinions of multiple sclerosis (MS) nurses about their role in treatment decision making and about the importance of different attributes of autoinjectors used to deliver first-line parenteral therapy.

Methods: The survey involved 52 MS nurses in different practice settings in France, Germany, Italy, the UK, and the USA. Nurses described their role in patient education and in treatment decision making. They also rated the importance of nine prespecified attributes of autoinjectors and stated their preference, both overall and by attribute, for one of two autoinjectors used to deliver interferon $\beta-1 b$ (ExtaviPro ${ }^{\circledR} 30 \mathrm{G}$ and Betacomfort $\left.{ }^{\circledR}\right)$. Nurses' preferences were compared with those previously collected from patients using an identical questionnaire.

Results: There were pronounced differences between practice settings and between countries in the opinions of MS nurses about their influence on treatment decision making. Nurses considered themselves instrumental in helping patients decide between treatment options offered by neurologists. Of the nine autoinjector attributes, nurses rated "reliable to use" as most important, followed by attributes associated with convenience ("easy to operate," "ergonomic shape," "reach" [of injection sites], and "one-handed injection"). Nurses' and patients' rankings of attributes were closely aligned. For the nine attributes, $74 \%-98 \%$ of nurses preferred ExtaviPro ${ }^{\circledR} 30 \mathrm{G}$ to Betacomfort ${ }^{\circledR}, 94 \%$ preferring ExtaviPro ${ }^{\circledR} 30 \mathrm{G}$ overall. Nurses showed a greater preference than patients for ExtaviPro ${ }^{\circledR} 30 \mathrm{G}$ with respect to "easy to operate" (92\% vs 78\%), "intuitive to use" (98\% vs 78\%), and "attractive design" (98\% vs $83 \%$; $P<0.05$, all), but preference rates were otherwise similar across the two groups. The most common reasons in both groups for preferring ExtaviPro ${ }^{\circledR} 30 \mathrm{G}$ to Betacomfort ${ }^{\circledR}$ were "easy to use" and "ergonomic shape."

Conclusion: MS nurses play a key role in patient guidance and education. Their preferences for ExtaviPro ${ }^{\circledR} 30 \mathrm{G}$ likely reflect their understanding of the challenges patients face when self-administering treatment.

Keywords: injections, interferon $\beta$, relapsing-remitting, self-administration, subcutaneous

\section{Introduction}

Following a diagnosis of multiple sclerosis (MS), patients are confronted with an uncertain prognosis. At this difficult time, they may need to make an informed decision about therapy if their treating physician offers them a choice. ${ }^{1}$ As specialized healthcare professionals, MS nurses play an important role in educating patients about their disease $^{2}$ and, increasingly, in discussing treatment options to help patients decide which therapy best suits their circumstances. ${ }^{3}$ In addition to being sensitive to the needs of 
patients and caregivers, MS nurses must understand both the likely clinical progression of MS and the benefits and drawbacks of different therapeutic options. ${ }^{4}$ This knowledge allows MS nurses to reassure patients before the start of treatment, facilitates monitoring and management of side effects, and underpins the advice that must be given when a patient's resolve to adhere to therapy weakens. ${ }^{3}$

Interferon $\beta$ preparations, which are administered by subcutaneous or intramuscular injection, are among the most frequently prescribed first-line disease-modifying therapies (DMTs) for relapsing forms of MS. ${ }^{5}$ Head-to-head evidence from Phase III studies indicates that high-dose, high-frequency interferon $\beta$ is more efficacious when injected every other day (Extavia ${ }^{\circledR}$; Novartis Pharma AG, Basel, Switzerland; Betaferon ${ }^{\circledR}$; Bayer Schering Pharma AG, Berlin, Germany) or three times weekly (Rebif ${ }^{\mathbb{B}}$; Merck Serono SA, Geneva, Switzerland) than when administered once weekly (Avonex ${ }^{\circledR}$; Biogen Idec, Weston, MA, USA). ${ }^{6,7}$

Injection site reactions (ISRs), such as itching, redness, and swelling with inflammation, ${ }^{8}$ are among the most common adverse events associated with interferon $\beta .{ }^{9}$ These issues, as well as injection-related anxiety and pain, ${ }^{10}$ have led to the introduction of thinner needles, which can mitigate ISRs, ${ }^{11}$ and autoinjectors, which standardize injection technique and deliver a controlled dose of medication. ${ }^{12}$ Studies show that autoinjectors can reduce the incidence and intensity of ISRs compared with manual administration $^{13}$ and that their use is strongly predictive of adherence to therapy. ${ }^{14}$ Patients have the option of using an autoinjector irrespective of which parenteral DMT they choose, but the designs and features of these devices differ considerably and may influence convenience and ease of use, and consequently adherence. Therefore, it is important that nurses are aware of these differences when helping patients to make informed treatment decisions.

The international survey reported here first assessed the extent to which nurses regard themselves as being involved in supporting patient choices in different practice settings across Europe and the USA, then evaluated which general attributes of autoinjectors nurses consider to be most important. It also recorded nurses' preferences when comparing the ExtaviPro ${ }^{\circledR} 30 \mathrm{G}$ autoinjector (Novartis Pharma AG) with the Betacomfort ${ }^{\circledR}$ autoinjector (Bayer Schering Pharma AG), both of which are used to self-administer interferon $\beta$-1b subcutaneously. Coinciding with the completion of this survey, ExtaviPro ${ }^{\circledR} 30 \mathrm{G}$ was first launched in Germany in February 2014 and subsequently across Europe, Canada, and the USA. The Betacomfort ${ }^{\circledR}$ device was widely available when this survey was undertaken. A set of questions identical to those reported here was used to examine the general attributes of autoinjectors and to compare ExtaviPro $^{\circledR} 30 \mathrm{G}$ and Betacomfort ${ }^{\circledR}$ in a patientpreference survey published in 2013 by Thakur et al. ${ }^{15}$ Therefore, nurses' responses to the survey can be compared with those previously reported by patients, to assess the degree of alignment.

\section{Methods}

This survey of specialist MS nurses was conducted between January 22 and February 24, 2014, in France, Germany, Italy, the UK, and the USA by an independent market research organization (Adelphi Research, Bollington, UK), in accordance with market research guidelines developed by the European Pharmaceutical Marketing Research Association and the Council of American Survey Research Organizations. For consistency, the countries chosen were the same as those selected for the related patient-preference survey. ${ }^{13}$ The questionnaire presented here was translated for use in France, Germany, and Italy, and both the original English questionnaire and these translations were approved by the sponsor (Novartis Pharma AG, Basel, Switzerland) before use. Conduct of the survey in the UK preceded those undertaken elsewhere, to provide an opportunity to revise the questionnaire before it was disseminated more widely (no revisions were made). All individuals provided written informed consent before participating in the survey.

\section{Eligibility criteria}

Individuals who gained their primary nursing qualification between 1976 and 2007, who had practiced as a specialist MS nurse for at least 3 years, and who provided informed consent to participate were recruited from specialist MS centers, hospitals, or office-based practices. Nurses were eligible if they saw at least 15 patients with MS per month. This quota had to include a minimum of ten patients with relapsing-remitting MS if the nurse was hospital based, or a minimum of five patients with relapsing-remitting MS if the nurse was office based. All participants were required to fulfill routinely a certain level of involvement in patient education, specifically, training patients to self-administer an injectable therapy and/or supporting patients in the treatment selection process by explaining method of administration, mechanism of action, possible side effects, and treatment initiation. Finally, all participants were required to have clinical experience of at least three of the five first-line injectable therapies but were ineligible if more than $75 \%$ of their 
patients were receiving the same first-line injectable therapy. Preference during the selection process was given to nurses who met these criteria and who also had clinical experience of oral or intravenous MS therapies.

\section{Interview protocol}

In each country, candidate screening and interview of those who met the eligibility criteria were conducted on a 1:1 basis at a central location by the same moderator. For candidates' convenience, the recruitment process targeted practices accessible from each of these central locations and no quotas were placed on the different types of practice setting involved. The survey consisted of four sections (Table 1). In the first section, each nurse's clinical background was confirmed, as was their role in educating patients about their disease and in deciding which treatment patients would receive. This included scoring out of 100 the relative influence that the nurse, the physician, the patient, and any other individuals have in this process.

In the second section (the results of which are not reported here), participants were asked which support services or materials they found useful and which services or materials they would like made available. They were then asked for their opinion about the efficacy of different first-line parenteral DMTs, which treatments and autoinjectors are best suited to the majority of their patients, how important autoinjectors are in influencing a patient's treatment choice, and why they thought that certain autoinjectors are better than others.

In the third section, participants scored nine prespecified attributes of autoinjectors on a scale of 1 (not at all important) to 7 (extremely important) and were given the opportunity to suggest up to three further attributes and rate their importance on the same scale. They were also asked for their reaction to the results of a survey undertaken previously among patients who used the same set of questions. ${ }^{13}$

In the fourth section, participants were shown ExtaviPro ${ }^{\circledR}$ $30 \mathrm{G}$, both disassembled in kit form (as patients would receive it at first use) and in the assembled form (primed with saline solution) to afford an opportunity to test the injection mechanism. Participants were then asked for their overall reaction to the device and (if appropriate) how it compared with the previous Extavia ${ }^{\circledR}$ autoinjector (ExtaviJect ${ }^{\circledR}$ 30G). They were then shown the Betacomfort ${ }^{\circledR}$ autoinjector and asked to state whether they preferred ExtaviPro ${ }^{\circledR} 30 \mathrm{G}$ or Betacomfort ${ }^{\mathbb{R}}$ based on each of the nine prespecified attributes considered in Section 3 of the interview. They were also asked which device they preferred overall, the main reason for this choice, and their reaction to the results of the same exercise that was conducted as part of the patients' survey. ${ }^{13}$ Finally, participants were asked how ExtaviPro ${ }^{\circledR} 30 \mathrm{G}$ compares with the devices they regarded as currently the best on the market.

\section{Statistical analysis}

The analysis population included all participants who completed the survey. For the autoinjector-attribute and autoinjector-preference surveys, and for comparisons made between the nurse and patient surveys,${ }^{15}$ a minimum sample size of 30 individuals was required to provide a robust statistical test at the $5 \%$ level. The significance of differences between subgroups of dichotomous data, such as autoinjector preference, was estimated using the $z$-test at the $5 \%$ level $(P=0.05)$. The significance of differences between subgroups of continuous data, such as mean overall attribute scores, was estimated using the Student's $t$-test at the $5 \%$ level $(P=0.05)$. All other statistics are reported only descriptively.

\section{Results \\ Nurse disposition}

A total of 52 specialist MS nurses from France $(n=12)$, Germany $(\mathrm{n}=10)$, Italy $(\mathrm{n}=10)$, the UK $(\mathrm{n}=10)$, and the USA $(n=10)$ participated in the survey. Just over half of the nurses were working in a university hospital at the time of the survey $(\mathrm{n}=28 ; 54 \%)$. The remaining participants were working in office-based or community practices $(n=8)$, general hospitals $(n=7)$, specialist MS centers $(n=7)$, or private hospitals $(n=2)$. A breakdown of practice settings by country is shown in Table 2.

\section{Role of nurses in different practice settings}

Nurses in specialist MS centers or university hospitals tended to perceive themselves as being more involved in the treatment decision-making process than did those in private or community hospitals. As well as differences associated with the practice setting, the survey indicated considerable international differences in the perceived level of influence of nurses and patients on treatment decisions and also in the prescribing patterns of physicians. Overall, nurses estimated that treating neurologists give their patients a choice of two or more DMTs in approximately $54 \%$ of cases. Nine of the ten nurses surveyed in the UK indicated that physicians offered a choice of at least two treatments, but only one of the ten nurses surveyed in Italy indicated that this was the case (Figure 1A). The survey showed that the involvement 
Table I Survey of specialist MS nurses' opinions and preferences

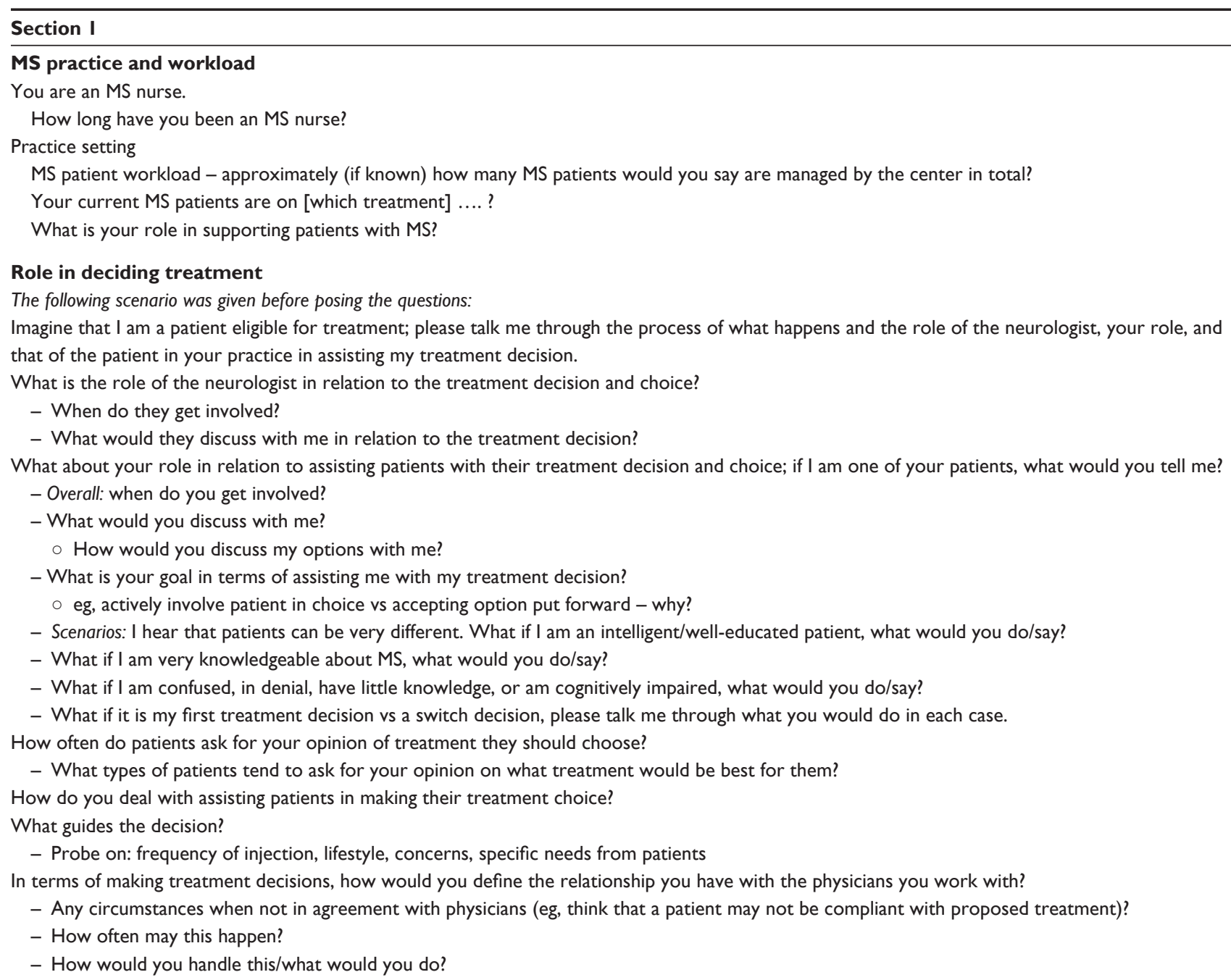

If you were to split 100 points between the patient, yourself, the neurologists, and any others who input into the treatment decision, how would you allocate the points?

- ie, the greater the number of points, the more the influence on the decision.

- Why did you split the points like this?

Please write in below:

Allocate 100 points - the more points allocated to a type of person, the more influential they are in the treatment decision

You (nurse):

Physician:

Patient:

Other (write in):

Total must equal 100

Section 2

Support service/material (if example brought)

Tell me about this specific example.

- What is it?

- Who is it from?

- When is it used/when useful?

Why do you find it useful/helpful?

In your view, what is it that makes this service/material particularly good?

- Why does it stand out to you?

Ask all about materials/support services that support nurses with:

- treatment options

- autoinjector options 
Table I (Continued)

If you had a magic wand, what materials or services from a manufacturer would truly impress you to assist with treatment choice?

- What would it be/look like and enable you to do?

- Is this need at all currently fulfilled by any manufacturer's services/materials?

And to assist with autoinjector choice - what would it be/look like and enable you to do?

Anything currently missing in services/materials?

Anything that could be improved?

\section{Treatment preference}

l'd now like to focus on the first-line MS autoinjectable treatments available on the market: Betaferon ${ }^{\circledR} /$ Betaseron $^{\circledR}$, Rebif $^{\circledast}$, Extavia ${ }^{\circledR}$, Avonex $^{\circledR}$, and Copaxone ${ }^{\circledR}$. In your view, are there any differences in efficacy between these treatments?

$$
\text { - Why? }
$$

What do you think about the high-dose/high-frequency treatments?

The moderator was asked to note which treatments nurses view as similar in efficacy and whether any are considered more efficacious than Avonex ${ }^{\circledR}$ and Copaxone $^{\circledR}$; also whether they recognized some as high dose/high frequency (ie, Rebif ${ }^{\circledR} 44 \mu \mathrm{g}$ three times a week, Betaferon/Betaseron ${ }^{\circledR}$, Extavia ${ }^{\circledR}$ ).

In which ways do treatments differ?

Which treatment do you consider to be best for the majority of your patients? Why?

\section{Treatment (tick most preferred for majority of patients)}

Betaferon ${ }^{\circledR} /$ Betaseron $^{\circledR}$

\section{Rebif ${ }^{\circledast}$}

Avonex $^{\circledR}$

Extavia $^{\circledR}$

Copaxone $^{\circledast}$

Which autoinjector do you consider to be the best for the majority of your patients? Why? (Mark favorite and then tick which you view as best/worst.)

\begin{tabular}{|c|c|c|c|c|c|}
\hline Treatment & Autoinjector & $\begin{array}{l}\text { Current favorite } \\
\text { for majority } \\
\text { of patients }\end{array}$ & Best/leading & $\begin{array}{l}\text { Worst/lagging } \\
\text { behind }\end{array}$ & $\begin{array}{l}\text { In which league (best or } \\
\text { worst) does ExtaviPro }{ }^{\circledR} \\
\text { 30G fit? }\end{array}$ \\
\hline Betaferon ${ }^{\circledR /}$ & Betacomfort $^{\circledR}$ & & & & \\
\hline Betaseron $^{\circledast}$ & Other: write in & & & & \\
\hline \multirow[t]{5}{*}{ Rebif $^{\circledR}$} & RebiSmart $^{\mathrm{TM}}$ & & & & \\
\hline & RebiDose $^{\mathrm{TM}}$ & & & & \\
\hline & RebiSlide $^{\mathrm{TM}}$ & & & & \\
\hline & Rebiject $^{\text {TM }}$ II & & & & \\
\hline & Other: write in & & & & \\
\hline \multirow[t]{2}{*}{ Avonex ${ }^{\circledR}$} & Avonex ${ }^{\circledR}$ pen & & & & \\
\hline & Other: write in & & & & \\
\hline \multirow[t]{2}{*}{ Extavia $^{\circledR}$} & ExtaviPro $^{\circledR} 30 \mathrm{G}$ & & & & \\
\hline & Other: write in & & & & \\
\hline Copaxone $^{\circledR}$ & Copaxone ${ }^{\circledR}$ Autoinjector II & & & & \\
\hline
\end{tabular}

From your experience, how important are autoinjectors to patients' ultimate treatment choices?

$$
\text { - Why? }
$$

Now, thinking of all the autoinjectors that you are familiar with and are available on the market, which do you view as being:

- the best (lead the way)

- the worst (lag behind)?

Why do you think this?

\section{Section 3}

Differentiation/important aspects for a new autoinjector

I have a list of features for you to consider. Please rate the importance of each in an autoinjector using a scale of I-7.

- I= not at all important and $7=$ extremely important.

- Please feel free to add any features you feel are important yet missing.

\section{Importance scale}

Not at all Neither/nor

An ergonomic shape: by this, I mean a design that is well adapted to your hand and therefore is easy to handle

$$
\begin{array}{lllll}
1 & 2 & 3 & 4 & 5
\end{array}
$$

The ability to read any information shown on the autoinjector, eg, the injection window or the needle depth

I 2

3

4 5 6

Extremely $6 \quad 7$

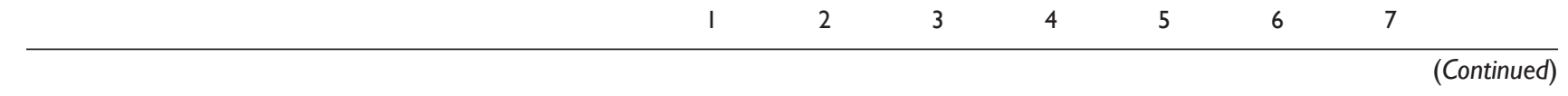


Table I (Continued)

\begin{tabular}{|c|c|c|c|c|c|c|c|}
\hline Reliable to use & 1 & 2 & 3 & 4 & 5 & 6 & 7 \\
\hline \multicolumn{8}{|c|}{ Intuitive to use: by this, I mean that you can understand how to use the autoinjector with little or no instruction } \\
\hline & 1 & 2 & 3 & 4 & 5 & 6 & 7 \\
\hline Overall, easy to operate & 1 & 2 & 3 & 4 & 5 & 6 & 7 \\
\hline \multicolumn{8}{|c|}{ One-handed injection: the ability to use the autoinjector with one hand for injection } \\
\hline & I & 2 & 3 & 4 & 5 & 6 & 7 \\
\hline Reach: the ability to reach all injection sites on your body & I & 2 & 3 & 4 & 5 & 6 & 7 \\
\hline An attractive design & 1 & 2 & 3 & 4 & 5 & 6 & 7 \\
\hline Other (write in): & 1 & 2 & 3 & 4 & 5 & 6 & 7 \\
\hline Other (write in): & I & 2 & 3 & 4 & 5 & 6 & 7 \\
\hline Other (write in): & I & 2 & 3 & 4 & 5 & 6 & 7 \\
\hline
\end{tabular}

l'd now like to share with you the results from a market research study we conducted with 20I MS patients who we asked to do the same exercise as you just have.

What's your reaction to these results?

- Any areas of difference with your ratings that surprise you? Why?

\section{Section 4}

\section{Reactions to ExtaviPro ${ }^{\circledR} 30 \mathrm{G}$}

In this last part, I would like to focus our discussion on this new autoinjector for Extavia ${ }^{\circledR}$, which is called ExtaviPro ${ }^{\circledR} 30 \mathrm{G}$. I have here the actual autoinjector along with a syringe prefilled with saline solution, which you are welcome to look at/try the injection process if you wish to do so.

The respondent was presented with:

- autoinjector in two parts inside leather wallet with instruction leaflet (rather than the booklet)

- autoinjector with prefilled syringe (ensure that the nurse doesn't dry fire the autoinjector that you gave them in two pieces for them to have the opportunity to assemble)

Note: trying the injection was optional and at the discretion of the nurse.

\section{Appearance of device}

Any spontaneous comments, questions?

Handling of device

Any spontaneous comments?

Does the participant intuitively know how to handle the device?

Is everything being used the right way around?

\section{Reading instructions}

Any questions?

Anything unclear on the instructions?

Does the participant refer back to the instructions? At which point?

\section{Use of device}

Do they hold the device correctly? If not, what do they do differently?

How many attempts were needed to perform injection correctly?

\section{Any other observations}

\section{Overall reactions}

How appealing is the autoinjector to you overall?

Why?

Any particular benefits?

Any areas stand out?

Any drawbacks?

Comparison with previous Extavia ${ }^{\circledR}$ autoinjector (if familiar with it)

How does ExtaviPro ${ }^{\circledR} 30 \mathrm{G}$ compare with the previous Extavia ${ }^{\circledR}$ autoinjector?

\section{Quantitative preference test vs Betacomfort ${ }^{\circledR}$}

I'd now like to ask you about your preference for the ExtaviPro ${ }^{\circledR} 30 \mathrm{G}$ or Betacomfort ${ }^{\circledR}$ autoinjector, which I have here. Please review the two devices using the same important features as discussed earlier.

Betacomfort ${ }^{\circledR}$ was placed on the table so that it could be compared with ExtaviPro ${ }^{\circledR} 30 \mathrm{G}$.

(Continued) 
Table I (Continued)

Thinking of the two autoinjectors on display, Betacomfort ${ }^{\circledR}$ and ExtaviPro ${ }^{\circledR} 30 \mathrm{G}$, I now have some questions about your preference. When answering these questions, I would like you to think only about the autoinjectors themselves, not the drugs they administer or their effect. For each feature below, please indicate which autoinjector performs better.

Attribute

An ergonomic shape: by this, I mean a design that is well adapted to your hand and therefore is easy to handle The ability to read any information shown on the autoinjector, eg, the injection window or the needle depth

Reliable to use

Intuitive to use: by this, I mean that you can understand how to use the autoinjector with little or no instruction Overall, easy to operate

One-handed injection: the ability to use the autoinjector with one hand for injection

Reach: the ability to reach all injection sites on your body

The feel of the autoinjector's tip on your skin (ie, the nozzle)

An attractive design

Other (write in):

Other (write in):

Other (write in):
Which autoinjector performs better on each attribute? Betacomfort $^{\circledR} \quad$ ExtaviPro $^{\circledR}$ is better $30 \mathrm{G}$ is better

Now, overall which would you prefer to use for injections to treat MS?

Please circle the code of the device you prefer:

Betacomfort ${ }^{\circledR}$...

ExtaviPro ${ }^{\circledR} 30 \mathrm{G}$ ...l

Autoinjector $[\ldots .$.$] is your preferred choice. What is the main reason for your choice?$

Attribute Circle the one reason that triggers your preference. If the main reason is not listed, please write it under "Other" An ergonomic shape: by this, I mean a design that is well adapted to your hand and therefore is easy to handle

The ability to read any information shown on the autoinjector, eg, the injection window or the needle depth

Reliable to use

Intuitive to use: by this, I mean that you can understand how to use the autoinjector with little or no instruction

Overall, easy to operate

One-handed injection: the ability to use the autoinjector with one hand for injection

Reach: the ability to reach all injection sites on your body

The feel of the autoinjector's tip on your skin (ie, the nozzle)

An attractive design

Other (write in):

$\begin{array}{ll}\text { I } & 2 \\ \text { I } & 2 \\ \text { I } & 2 \\ \text { I } & 2 \\ \text { I } & 2 \\ \text { I } & 2 \\ \text { I } & 2 \\ \text { I } & 2 \\ \text { I } & 2 \\ \text { I } & 2 \\ \text { I } & 2\end{array}$

l'd now like to share with you the results from the market research study we conducted with 20 I MS patients who we asked to do the same exercise as you just have.

What's your reaction to these results? Any areas of difference with your preference that surprise you? Why?

Now, let's imagine I am a new patient in your care and you are talking me through my autoinjector options. Let's imagine the choice is between [name the participant's favorite autoinjector] and ExtaviPro ${ }^{\circledR} 30 \mathrm{G}$. What would you say to me?

- What would you say about ExtaviPro ${ }^{\circledR} 30 \mathrm{G}$ specifically vs [name favorite]?

How does this new autoinjector make you feel about introducing Extavia ${ }^{\circledR}$ as a high-dose/high-frequency treatment to patients?

Could you see yourself recommending it? Why?

Abbreviation: MS, multiple sclerosis.

of patients and nurses in treatment decisions was greatest in the UK and smallest in Italy. In France, Germany, and the USA, estimates of involvement fell between these extremes and were similar in each country (Figure 1B).

The survey also recorded a similar pattern regarding the frequency with which patients solicit advice from their nurse about treatment. Nine of the ten nurses surveyed in the UK reported that patients "very often ask", "What would you do?". Only one of the ten nurses surveyed in Italy reported this, and frequencies were at an intermediate level in France (five nurses out of 12 surveyed), Germany (three of ten nurses surveyed), and the USA (three of ten nurses surveyed). In situations in which neurologists offered patients more than one treatment option, the nurse's role was to discuss these options in depth with the patient to help them reach a decision. As part of this process, about $50 \%$ of nurses surveyed in each country showed patients the autoinjector used to administer the treatments recommended by the neurologist, although 
Table 2 Number of nurses from each type of practice setting by country

\begin{tabular}{lllllll}
\hline & $\begin{array}{l}\text { MS specialist } \\
\text { center }\end{array}$ & $\begin{array}{l}\text { University } \\
\text { hospital }\end{array}$ & $\begin{array}{l}\text { General } \\
\text { hospital }\end{array}$ & $\begin{array}{l}\text { Private } \\
\text { hospital }\end{array}$ & $\begin{array}{l}\text { Office-based/ } \\
\text { community practice }\end{array}$ \\
\hline France & - & 9 & 1 & 2 & - & 12 \\
Germany & 2 & 3 & 2 & - & 3 & 10 \\
Italy & - & 5 & 3 & - & 2 & 10 \\
UK & 1 & 7 & 1 & - & 1 & 10 \\
USA & 4 & 4 & - & - & 2 & 10 \\
Total & 7 & 28 & 7 & 2 & 8 & 52 \\
\hline
\end{tabular}

Abbreviation: MS, multiple sclerosis.

this was not generally the practice in Italy. Having helped the patient to reach a decision, or when neurologists recommended only one treatment, the nurse's role was to reassure and educate the patient about the chosen treatment and to monitor and encourage adherence to treatment at follow-up consultations.

\section{Prespecified autoinjector attributes}

The three attributes ranked most highly by nurses were "reliable to use" (mean score of 6.7 out of a maximum possible score of 7.0), followed by "easy to operate" and "ergonomic shape" (both with a mean score of 6.6; Figure 2). Comparison of the mean attribute scores from this survey with those from 201 patients who responded to an identical survey ${ }^{15}$ indicated agreement between the two groups that "reliable to use" and "easy to operate" are the most important general attributes of autoinjectors. Nurses placed significantly greater importance than patients on "ergonomic shape" (mean scores of 6.6 and 6.3 , respectively; $P<0.05$ ) and, conversely, attached significantly less importance than patients to "one-handed injection" (mean scores of 6.2 and 6.5, respectively; $P<0.05$ ). Nurse and patient scores for "reach" $(6.4$, both) and "intuitive to use" (6.1 and 6.2, respectively) indicated good agreement about the importance of being able to reach all injection sites on the body and to use the autoinjector with little or no instruction. Nurses and patients also agreed that "ability to read display" (mean scores of 6.0 and 5.9, respectively), "feel of autoinjector's tip" (mean scores of 4.6 and 5.3, respectively; $P<0.05$ ), and "attractive design" (mean scores of 4.1 and 4.0, respectively) were the least important attributes.

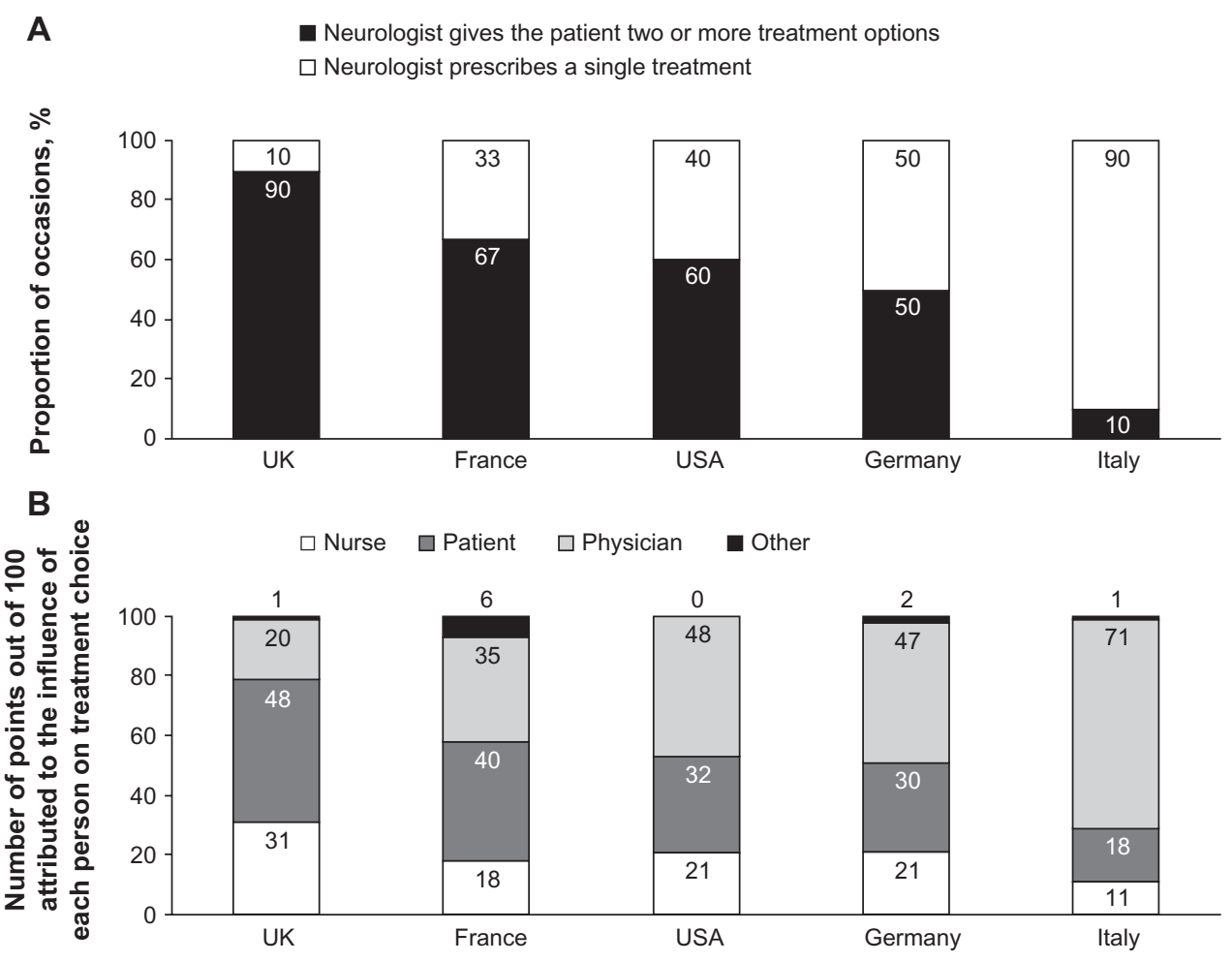

Figure I Nurses' estimation of $(\mathbf{A})$ the proportion of occasions when the treating neurologist prescribes single or multiple treatment options and (B) the estimated influence of different stakeholders on treatment choice by country. 


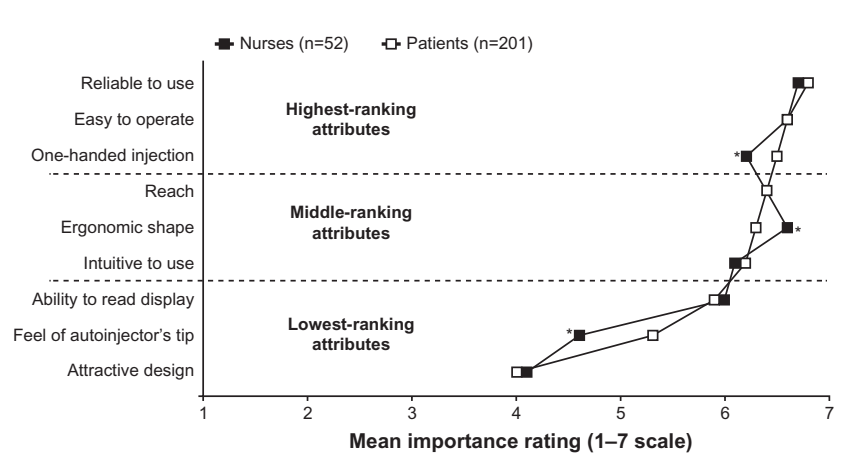

Figure 2 Mean scores given by nurses and patients for prespecified general attributes of autoinjectors.

Notes: Highest-ranking, middle-ranking, and lowest-ranking attribute categories are based on patient responses. ${ }^{15} * P<0.05$, for the difference between nurses' and patients' mean scores.

\section{Autoinjector preference}

Most nurses (94\%; $n=49 / 52)$ and patients $(86 \% ; n=173 / 201)$ indicated that they preferred ExtaviPro ${ }^{\circledR} 30 \mathrm{G}$ to Betacomfort $^{\mathbb{R}}$ (Figure 3). The same preference was also recorded when considering each of the nine prespecified attributes, the proportions of nurses and patients expressing a preference for ExtaviPro ${ }^{\circledR}$ $30 \mathrm{G}$ ranging from $74 \%$ to $98 \%$ (Figure 3). Proportionately more nurses than patients preferred ExtaviPro ${ }^{\circledR} 30 \mathrm{G}$ for the attributes "easy to operate," "intuitive to use," and "attractive design" (all $P<0.05$ ). Similar proportions of nurses and patients expressed a preference for ExtaviPro ${ }^{\circledR} 30 \mathrm{G}$ over Betacomfort ${ }^{\circledR}$ for all other attributes ("reliable to use," "onehanded injection," "reach," "ergonomic shape," "ability to read display," and "feel of autoinjector's tip").
Among the 49 nurses and 173 patients who preferred ExtaviPro $^{\circledR} 30 \mathrm{G}$ to Betacomfort ${ }^{\circledR}$, the reasons most frequently given in both groups were the attributes "easy to operate" (35\% and $22 \%$, respectively) and "ergonomic shape" (27\% and $28 \%$, respectively; Figure 4 ). For other attributes, the trend was mostly similar among nurses and patients in the proportions citing each as the reason for preferring ExtaviPro $^{\circledR}$ 30G.

\section{Discussion}

This study, which surveyed 52 specialist MS nurses from a variety of practice settings in Europe and the USA, revealed that there are pronounced differences, both internationally and by practice setting, in the perceived degree of involvement of nurses in the treatment decision-making process. In addition, nurses' opinions were recorded regarding the importance of attributes of autoinjectors used to administer first-line parenteral DMTs, and these were found to be closely aligned with those expressed by patients in a previous identical survey. ${ }^{15}$

In terms of nurses' perceived involvement in the treatment decision-making process, it seems likely that the international variation observed reflects the differing roles fulfilled by MS nurses in specific countries, but it may also reflect some underlying cultural differences. Nurses can play a critical role in educating patients about their disease and the treatment they are receiving ${ }^{2}$ and usually have more frequent clinical contact with patients than do physicians. ${ }^{16}$ Nurses are

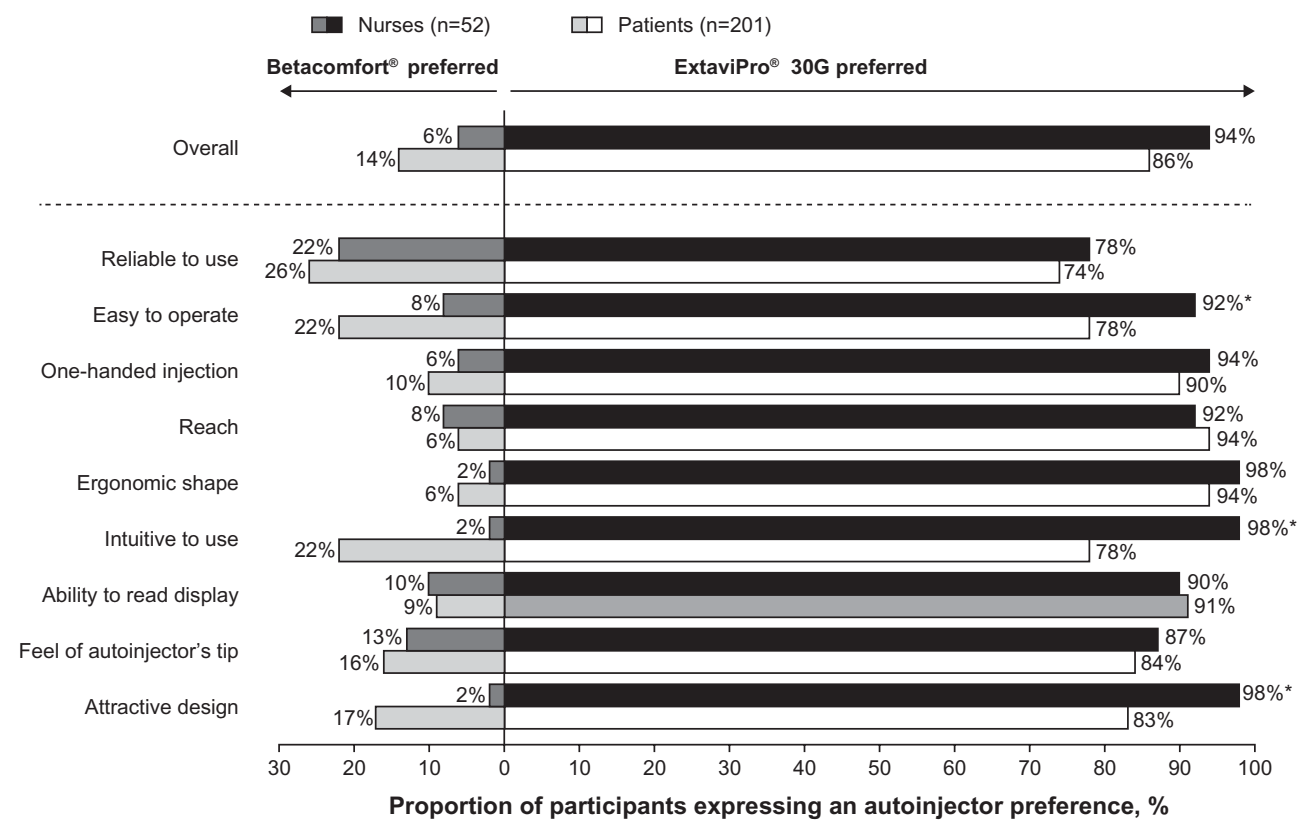

Figure 3 Proportion of nurses and patients expressing an autoinjector preference, both overall and by attribute. Note: $* P<0.05$, for the difference between the proportion of nurses and patients expressing a preference. 


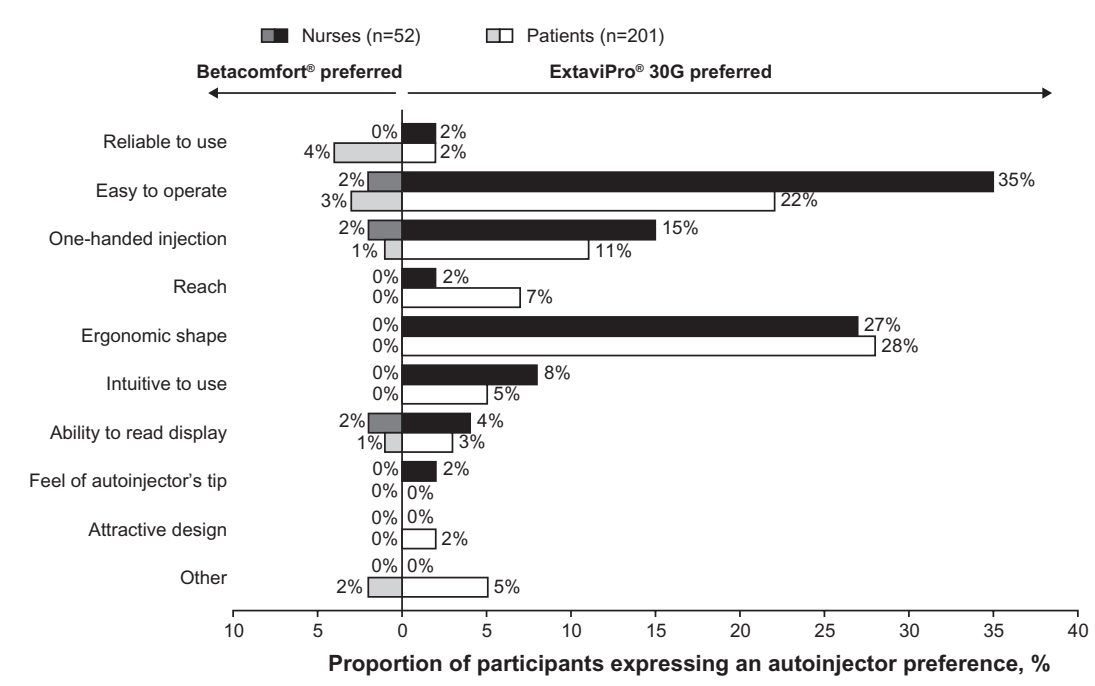

Figure 4 Proportion of nurses and patients citing each prespecified attribute as the main reason for their overall preference of autoinjector.

therefore well placed to understand each patient's circumstances and how their disease affects them. When a physician presents a patient with a number of treatment options, it is crucial that the patient makes an informed choice. This is one of the occasions when a nurse's influence on the treatment decision-making process is pivotal, helping patients to match the treatment options available with their needs.

This survey suggested that most neurologists in the UK give their patients the choice of two or more DMTs. Correspondingly, the survey also indicated that nurses in the UK perceived their and their patients' levels of involvement in treatment decisions to be greater than did their counterparts surveyed in the other countries. Nurses surveyed in the UK were also those most commonly asked for guidance by their patients regarding a treatment decision. Anecdotally, nurses reported that they avoid making specific recommendations regarding treatments and, instead, try to guide patients to make their own decisions based on an understanding of the likely disease course and on their lifestyle and preferences. Several nurses commented that allowing patients to reach their own decision maximizes the likelihood of adherence to treatment. In contrast to the situation in the UK, it seems that very few neurologists in Italy offer their patients two or more treatment options. Consistent with this, Italian nurses and their patients appeared to have the least involvement in treatment choice among the countries surveyed. A factor that may contribute to such a marked international difference is that specialist MS nurses have been operating in the UK for several years but have not yet been introduced in Italy. Specialist MS nurses are also established in the USA and are being introduced in Germany.
When an MS nurse helps a patient to choose between firstline parenteral DMTs, the attributes of the autoinjector used for a given therapy and the nurse's opinion of the device may both influence the patient's decision. In terms of attributes, an autoinjector that can be operated intuitively and that has a clear, simple display may be favored by patients with cognitive dysfunction or visual impairment. A patient with manual dexterity issues (which often manifest asymmetrically in MS) is likely to need an autoinjector that is of a size and design suitable for one-handed use. A device in which the needle tip is not exposed until the moment of injection may suit individuals with poor vision or dexterity, as well as patients who are trypanophobic. A well-informed MS nurse will be able to discuss such factors with patients, with the two aims of minimizing ISRs, anxiety, and accidental needle-stick injuries and of maximizing adherence to treatment. It was both important and reassuring to find a high level of agreement between nurses and patients in the autoinjector-attribute and autoinjector-preference surveys. As the two groups were surveyed separately, the alignment of their opinions shows that nurses understand the needs and preferences of their patients very well and guide their choice of treatment accordingly.

Consistent with what was reported in the patient survey, ${ }^{15}$ nurses rated "reliable to use" as the most important attribute of an autoinjector, followed by attributes associated with ease of use and convenience. There were, however, some discrepancies between the two groups; nurses awarded "one-handed injection" a slightly lower score and an "ergonomic shape" a slightly higher score than did patients. Patients placed more emphasis than nurses on being able to inject in a one-handed manner, which reflects a desire to maintain independence. 
Some of the eight injection sites can be difficult to reach without the assistance of a caregiver, ${ }^{17}$ and clearly this problem would be exacerbated if a device requires two hands to operate it instead of one.

Nurses' and patients' preferences were similar when choosing between two autoinjectors used to administer interferon $\beta-1 \mathrm{~b}$. When considering each of the nine prespecified attributes of autoinjectors, proportionately more nurses expressed a preference for ExtaviPro ${ }^{\circledR} 30 \mathrm{G}$ than for Betacomfort $^{\circledR}$, and $94 \%$ of nurses preferred ExtaviPro ${ }^{\circledR} 30 \mathrm{G}$ overall. In addition, most patients preferred ExtaviPro ${ }^{\circledR} 30 \mathrm{G}$ to Betacomfort ${ }^{\circledR}$ when considering each attribute, though there were some differences in the proportions of patients and nurses expressing this preference. Overall, $86 \%$ of patients preferred ExtaviPro ${ }^{\circledR} 30 \mathrm{G}$ to Betacomfort ${ }^{\circledR}$. This clear preference for ExtaviPro ${ }^{\circledR} 30 \mathrm{G}$ over Betacomfort ${ }^{\circledR}$ highlights how influential the design of autoinjector devices can be, given that both deliver the same treatment. It also highlights the importance of understanding the challenges that patients with MS face when looking for ways to facilitate adherence to treatment.

Our survey provides reassurance that nurses' understanding of patients' needs is well aligned with needs independently identified by patients, but it also reveals some of the international variations in the role of MS nurses. Market research methods such as this can yield valuable real-world data, but our survey has limitations. Relatively few countries were represented, but these were chosen to align with the related patient-preference survey ${ }^{13}$ and are among the most populous nations where these MS therapies are approved. No quotas were placed on site selection, so although a variety of practice settings were represented, the data are not weighted to reflect the relative proportions of each practice setting by country. Eligibility criteria for participants were imposed in order to identify nurses with extensive experience of treating patients with relapsingremitting MS, but these criteria were defined by the sponsor and may therefore be subject to bias. Sections 1 and 2 of the questionnaire are discussion guides designed by the sponsor in conjunction with the participating market research organization and included questions that were qualitative or semiquantitative. Therefore, the information gathered is only potentially indicative of any trends discussed. Affording anonymity to the participants and conducting interviews on a $1: 1$ basis provides reassurance that each set of responses genuinely reflects each individual's opinion. Sections 3 and 4 of the questionnaire are predominantly identical to the related patient-preference survey and are therefore subject to the limitations previously reported. ${ }^{13}$ The number of individuals surveyed in each country was relatively small, so this must be considered particularly when any international comparisons are made. Where statistics are reported without assessment of significance, they are used only descriptively.

In conclusion, the influence that nurses have in the MS treatment decision-making process varies considerably by country, but there was scope in all countries included in the survey for nurses to be involved in supporting some patients to make informed treatment decisions. Based on their perception of the importance of different attributes of autoinjectors, MS nurses' understanding of the needs of their patients is uniformly high. When a choice is to be made between first-line parenteral DMTs, the attributes of the autoinjector may influence the decision based on an individual's disease-related impairments and circumstances. As a regular point of contact for patients with MS, the nurse must try to gauge each patient's circumstances and needs to ensure that they can help the patient to select the most appropriate treatment.

\section{Acknowledgments}

The authors would like to thank the nurses who participated in this survey. Writing and editorial support was provided by Jeremy Bright of Oxford PharmaGenesis ${ }^{\text {TM }}$ Ltd and was funded by Novartis Pharma AG.

\section{Disclosure}

The study was funded by Novartis Pharma AG. Elisabetta Verdun di Cantogno and Kunal Thakur are employees of Novartis Pharma AG. At the time the survey was undertaken, Laure Manuel was an employee of Adelphi Research Ltd, which was funded by Novartis Pharma AG to coordinate this survey. Mark Tomlinson receives funding as a consultant to Novartis Pharma AG. The authors report no other conflicts of interest in this work.

\section{References}

1. Solari A. Effective communication at the point of multiple sclerosis diagnosis. Mult Scler. 2014;20(4):397-402.

2. Halper J, Holland NJ. Educating the patient and family. In: Halper J, Holland NJ, editors. Comprehensive Nursing Care in Multiple Sclerosis. 3rd ed. New York: Springer Publishing Company; 2011:29-42.

3. Burke T, Dishon S, McEwan L, Smrtka J. The evolving role of the multiple sclerosis nurse: an international perspective. Int J MS Care. 2011;13(3):105-112.

4. Costello K, Halper J, Harris C. Nursing Practice in Multiple Sclerosis: A Core Curriculum. New York: Demos Medical Publishing; 2003. 
5. Hanson KA, Agashivala N, Wyrwich KW, Raimundo K, Kim E, Brandes DW. Treatment selection and experience in multiple sclerosis: survey of neurologists. Patient Prefer Adherence. 2014;8:415-422.

6. Durelli L, Verdun E, Barbero P, et al; Independent Comparison of Interferon (INCOMIN) Trial Study Group. Every-other-day interferon beta-1b versus once-weekly interferon beta-1a for multiple sclerosis: results of a 2-year prospective randomised multicentre study (INCOMIN). Lancet. 2002;359(9316):1453-1460.

7. Panitch H, Goodin DS, Francis G, et al. Randomized, comparative study of interferon beta-1a treatment regimens in MS: the EVIDENCE Trial. Neurology. 2002;59(10):1496-1506.

8. McEwan L, Brown J, Poirier J, et al. Best practices in skin care for the multiple sclerosis patient receiving injectable therapies. Int J MS Care. 2010;12(4):177-189.

9. Giovannoni G, Southam E, Waubant E. Systematic review of diseasemodifying therapies to assess unmet needs in multiple sclerosis: tolerability and adherence. Mult Scler. 2012;18(7):932-946.

10. Treadaway K, Cutter G, Salter A, et al. Factors that influence adherence with disease-modifying therapy in MS. J Neurol. 2009;256(4): $568-576$.

11. Jaber A, Bozzato GB, Vedrine L, Prais WA, Berube J, Laurent PE. A novel needle for subcutaneous injection of interferon beta-1a: effect on pain in volunteers and satisfaction in patients with multiple sclerosis. BMC Neurol. 2008;8:38.

12. Lugaresi A. Addressing the need for increased adherence to multiple sclerosis therapy: can delivery technology enhance patient motivation? Expert Opin Drug Deliv. 2009;6(9):995-1002.
13. Brochet B, Lemaire G, Beddiaf A, et l'Epicure Study Group. Réduction des réactions cutanées aux points d'injection avec deux auto-injecteurs chez des patients ayant une sclérose en plaques rémittente débutant un traitement par interféron bêta-1b: étude randomisée en cross-over. [Reduction of injection site reactions in multiple sclerosis (MS) patients newly started on interferon beta $1 \mathrm{~b}$ therapy with two different devices]. Rev Neurol (Paris). 2006;162:735-740. French.

14. Pozzilli C, Schweikert B, Ecari U, Oentrich W. Supportive strategies to improve adherence to IFN beta-1b in multiple sclerosis - results of the betaPlus observational cohort study. J Neurol Sci. 2011;307(1-2): 120-126.

15. Thakur K, Manuel L, Tomlinson M. Autoinjectors for administration of interferon beta-1b in multiple sclerosis: patient preferences and the ExtaviPro ${ }^{\text {TM }} 30 \mathrm{G}$ and Betacomfort ${ }^{\mathbb{R}}$ devices. Pragmatic Obs Res. 2013;4:19-26.

16. Hartung H-P, Ross AP. European nurse survey demonstrates significant disparities in nursing of multiple sclerosis patients and the need to benchmark standards for improved patient care. Mult Scler. 2010; 16 (Suppl 10):S331.

17. Extavia ${ }^{\circledR}$. (Interferon beta-1b) [prescribing information]. Novartis Pharmaceuticals Corporation, East Hanover, NJ, USA; 2012. Available at: https://www.pharma.us.novartis.com/product/pi/pdf/extavia.pdf. Accessed August 1, 2014
Pragmatic and Observational Research

\section{Publish your work in this journal}

Pragmatic and Observational Research is an international, peer-reviewed, open access journal that publishes data from studies designed to reflect more closely medical interventions in real-world clinical practice compared with classical randomized controlled trials (RCTs). The manuscript management system is completely online and includes a very quick and fair peer-review

\section{Dovepress}

system. Visit http://www.dovepress.com/testimonials.php to read real quotes from published authors. 